\title{
Sex differences in lung vulnerability to tobacco smoking
}

\author{
A. Langhammer*,\#, R. Johnsen\#, A. Gulsvik", T.L. Holmen*,\#, L. Bjermer ${ }^{+}$
}

Sex differences in lung vulnerability to tobacco smoking. A. Langhammer, R. Johnsen, A. Gulsvik, T.L. Holmen, L. Bjermer. (C)ERS Journals Ltd 2003.

ABSTRACT: Studies have indicated that females are more vulnerable to the deleterious effect of tobacco smoking than males. The current study aimed to investigate the associations between tobacco smoking and reported respiratory symptoms, self-rated health, and lung function by sex.

In $1995-199765,225$ subjects aged $\geqslant 20$ yrs $(71 \%$ of invited) attended for screening within the Nord-Trondelag Health Study. Among these, 10,941 subjects selected randomly or because they reported having asthma or asthma-related symptoms, participated in the Bronchial Obstruction in Nord-Trondelag study consisting of spirometry and a personal interview.

Tobacco smoking was associated with increased prevalence of respiratory symptoms, reduced lung function, and lower score on global self-rated health (SRH). Adjusted for smoking burden and lung function, females had a higher risk for reporting respiratory symptoms and lower SRH compared with males. Further, smoking burden was associated with a larger relative reduction in expiratory lung function in females than in males.

Females reported more symptoms and lower self-rated health compared with males with similar smoking burden. Even if smoking in females was associated with a larger reduction in per cent predicted lung function compared with males, this does not fully explain the higher symptom prevalence in females.

Eur Respir J 2003; 21: 1017-1023.
*Nord-Trøndelag Health Study Research Centre, Norwegian University of Science and Technology (NTNU), Verdal, " Dept of Community Medicine and General Practice, NTNU, Trondheim, "Dept of Thoracic Medicine, University of Bergen, Bergen, Norway. ${ }^{+}$Dept of Respiratory Medicine and Allergology, University Hospital, Lund, Sweden.

Correspondence: A. Langhammer, NordTrøndelag Health Study Research Centre, Norwegian University of Science and Technology, Neptunveien 1, N-7650 Verdal, Norway. Fax: 4774075181

E-mail: arnulf.langhammer@medisin.ntnu.no

Keywords: Lung function, respiratory symptoms, self-rated health, sex, tobacco smoking

Received: June 202002

Accepted after revision: January 292003

This study was supported by the Norwegian Research Council and AstraZeneca.
Some studies have reported higher vulnerability to the deleterious effects of tobacco smoking in females compared with males. These results include negative effect on lung growth [1], lower lung function in adulthood [2], increased bronchial responsiveness [3], higher rate of hospitalisation for chronic obstructive pulmonary disease [4], and higher risk of respiratory symptoms [5]. There are, however, conflicting reports on sex differences for the negative effect on lung function of tobacco smoking [2,6]. Even if there are sexrelated differences in perception, reporting and interpretation of respiratory symptoms and diseases [7], a symptom like shortness of breath is found to be associated with quality of life and to predict mortality equally well in both sexes [8]. It has therefore been proposed that respiratory symptoms are more related to general health in females and are more specific for respiratory and cardiac diseases in males.

The objective of this study was to analyse the effect of tobacco smoking on lung function, and to study the association between respiratory symptoms, lung function and global self-rated health (SRH) in males and females.

\section{Materials and methods}

In 1995-1997 all inhabitants of the Nord-Trøndelag County, Norway, aged $\geqslant 20$ yrs were invited to the adult part of the Nord-Trøndelag Health Study (HUNT). The invitation included a comprehensive questionnaire on health, diseases, symptoms and risk factors. At the screening station, a further questionnaire with more disease-specific questions was asked. Among the participants in the HUNT study, two groups were invited to the Bronchial Obstruction in Nord-Trøndelag (BONT) study, phase I including: 1) a 5\% random sample of the total population; and 2) a symptom group with positive answers to questions either on ever-asthma, ever-use of asthma medication or attacks of wheezing or breathlessness during the last 12 months. A third questionnaire focusing on respiratory symptoms was also given to those invited to the BONT study and those reporting persistent cough in questionnaire I (fig. 1). The questions concerning respiratory illnesses, diseases and smoking habits have been published previously [5]. The question on SRH; "How is your health at the moment?" could be answered as "poor", "not well", "well" and "very well" [9].

The BONT study phase I consisted of flow/volume spirometry and a structured, personal interview on respiratory symptoms, diagnosis and treatment. Flow/volume spirometry was recorded with three pneumotachographs (MasterScope spirometer, version 4.15; Erich Jaeger GmbH, Wuerzburg, Germany) by trained staff in accordance with recommendations by the American Thoracic Society [10]. The predicted forced expiratory volume in one second (FEV1) and forced vital capacity (FVC) were calculated using prediction equations estimated for this population [11].

The study was approved by the Regional Committee for Ethics in Medical Research and the Norwegian Data Inspectorate.

\section{Analysis}

Descriptive data are presented as mean \pm SD as well as mean and $95 \%$ confidence interval (CI). Analyses of variance were 


\begin{tabular}{|c|c|}
\hline \multicolumn{2}{|c|}{ Invited HUNT 92,936 subjects } \\
\hline \multicolumn{2}{|c|}{$\begin{array}{l}\text { Attending HUNT screening with Questionnaire } 1 \text { (Q1) } \\
65,225 \text { subjects }\end{array}$} \\
\hline${ }$ & 2 \\
\hline \begin{tabular}{|c|} 
Questionnaire 2 (Q2) \\
Delivered all \\
Answered: 57,316 subjects (87.9\%) \\
\end{tabular} & $\begin{array}{l}\text { Invited BONT phase I }(13,476) \\
\text { \#Random sample 3,296 } \\
\text { +Symptom group 10,063 }\end{array}$ \\
\hline $\begin{array}{c}\text { Questionnaire } 3(\mathrm{Q} 3) \\
\text { \#Random + १symptom group } \\
\text { Delieved } 15,803 \text { subjects } \\
\text { Answered: } 11,822 \text { subjects }(74.8 \%)\end{array}$ & $\begin{array}{l}\text { Participants BONT phase I } \\
\text { \#Random sample 2,791 (84.7\%) } \\
\text { +Symptom group 8,150 (80.1\%) } \\
\text { Q1: } 98.8 \% \text { Q2: 84.2\% Q3: } 70.3 \%\end{array}$ \\
\hline
\end{tabular}

Fig. 1. - Participants and responders of questionnaires in the NordTrøndelag Health Study (HUNT) and the Bronchial Obstruction in the Nord Trøndelag (BONT) study 1995-1997. \#: 5\% random sample of the total population; ": subjects reporting ever having had asthma or asthma-related symptoms during the last 12 months, or longstanding cough; ${ }^{+}$: subjects reporting ever having had asthma or asthma-related symptoms during the last 12 months.

used for continuous data. Linear regression analysis was used to evaluate the impact of independent variables on lung function, and logistic regression to evaluate the impact of independent variables on the risk of symptom reporting and global SRH. Interactions between the independent variables were tested and the results are reported where statistically significant. SRH was used as a dependent variable both in separate models for each level of SRH and as one dichotomised variable (negative $=$ poor or not well, positive $=$ well or very well) in the logistic regression models. Sex differences were tested including interactions in the regression models. In the analysis of the association between tobacco smoking and lung function, only never- and current smokers were included. For linear regression models, the assumptions of linearity and homogeneity were tested, and goodness of fits for logistic regression models were tested with Hosmer Lemeshow tests. All p-values were two-tailed, and a $\mathrm{p}<0.05$ was considered significant.

Estimation of the prevalence of symptoms in the population was restricted to the $5 \%$ random sample. In the further analyses the group reporting respiratory symptoms was also included.

Subjects, who reported both "ever-asthma" (having had asthma at one time or another) and attacks of wheezing or breathlessness during the last 12 months, were defined as having current asthma. Chronic bronchitis was defined as reported cough with phlegm in periods of at least 3 months during the last 2 yrs.

The smoking status was classified as never-smokers (never smoked daily), exsmokers (ceased smoking $\geqslant 1$ yrs earlier) and current daily smokers. The latter two groups were classified as ever-smokers. Number of pack-yrs was calculated as: years of smoking multiplied by number of cigarettes a day divided by 20 . Those reporting only current pipe smoking $(0.9 \%$ males and $0.1 \%$ females) or cigar/cigarillos smoking $(0.2 \%$ males and $0.1 \%$ females $)$ were categorised as current daily smokers, but number of pack-yrs could not be estimated.

\section{Results}

\section{Participants and smoking history}

In total, 65,225 subjects (71\%) attended the HUNT study and 10,941 subjects participated in BONT phase I (fig. 1). The
$5 \%$ random sample did not differ from the total screening population regarding demographical characteristics, respiratory symptoms and smoking habits except for a slightly higher prevalence of reported daily coughing (17.6 versus $15.8 \%$ ), chronic bronchitis (5.1 versus $4.0 \%$ ) and neversmokers (41.1 versus $38.3 \%$ ) in males, in the random sample (all $\mathrm{p}<0.05$ ).

Amongst all participants at the screening, there was a minor difference in prevalence of current smokers among females and males ( 30.6 versus $29.6 \%, \mathrm{p}=0.01$ ), and in the random and symptom group, a corresponding but nonsignificant difference was found (table 1). Amongst all participants, ever-smoking males reported a higher daily cigarette consumption (13.1 versus 9.7 cigarettes) and had started to smoke at a younger age (18.4 versus 19.8 yrs) compared with females $(\mathrm{p}<0.001)$. The current smoking females were significantly younger than males ( 45.7 versus $50.2 \mathrm{yrs}$ ), in contrast to never-smokers (52.7 versus $44.4 \mathrm{yrs}$ ) (both $\mathrm{p}<0.01$ ). Further, $64 \%$ of all participants reported exposure to passive smoking in childhood and 60\% reported this in adulthood. Amongst never-smokers, $48 \%$ of females and $35 \%$ of males reported exposure to passive smoking in adulthood $(\mathrm{p}<0.01)$.

\section{Respiratory symptoms, diagnosis and tobacco smoking}

Adjusted for age and body mass index (BMI), females had a significantly higher risk per 10 pack-yrs of reporting attacks of wheezing or breathlessness (odds ratio (OR) 1.38 versus $1.25)$, current asthma (1.30 versus 1.15$)$, and persistent cough (1.48 versus 1.32$)($ all $\mathrm{p}<0.01)$ compared with males, when all participants in the main screening were included in the analyses [5]. A similar relationship was found among participants at BONT phase I, and statistically significant differences were found even when an intermediate variable, such as lung function (FEV1 \% predicted) and the interaction term sex * FEV1 \% pred were included in the model (data not shown). Analyses of the interview data revealed that females, adjusted for age and BMI, had significantly greater risk than males of reporting wheezing (OR 1.38 (95\% CI 1.35-1.45) versus $1.25(1.20-1.30))$ and breathlessness (1.18 (1.11-1.24) versus 1.08 (1.04-1.12)) per 10 pack-yrs. Inclusion of the group (random sample or symptom group) as an independent variable did not alter these results.

Exposure to tobacco smoking in childhood was significantly associated with the risk of reporting attacks of wheezing or breathlessness in females $(1.20(1.10-1.30))$ but not in males, when age, pack-yrs, BMI, and smoking category (never, ex- or current smoker) were included as independent variables. Exposure to passive smoking after the age of $20 \mathrm{yrs}$, included in a similar model, was also associated with increased risk of these symptoms, but in this case, no difference with sex was found (1.23 (1.16-1.31)).

In the random sample, $8.7 \%$ of both females and males reported doctor-diagnosed asthma. Further, doctor-diagnosed chronic bronchitis/emphysema was reported by $2.3 \%$ females and $4.0 \%$ males $(\mathrm{p}<0.01)$, but the difference became statistically insignificant when adjusted for BMI, FEV1 \% pred and pack-yrs. Smoking burden was not associated with being given the diagnosis of asthma by a doctor, but the OR for the diagnosis of chronic bronchitis/emphysema was 2.3 per pack-yr in both sexes.

\section{Lung function and exposure to tobacco smoking}

Tobacco smoking was associated with lower lung function in all age groups, the greatest decline being found in current smokers (fig. 2a and b). Correspondingly, passive smoking after the age of $20 \mathrm{yrs}$, adjusted for age and pack-yrs, was 
Table 1. - Demographical data, lung function, smoke history, reported respiratory symptoms and global self-rated health (SRH), among participants in the Bronchial Obstruction in Nord-Trøndelag (BONT) study phase I random sample (5\% random sample of the total population) and symptom group (those reporting ever having had asthma, ever use of asthma medications or attacks of wheezing or breathlessness during the last 12 months)

\begin{tabular}{|c|c|c|c|c|}
\hline \multirow[t]{2}{*}{ Characteristics } & \multicolumn{2}{|c|}{$5 \%$ Random sample } & \multicolumn{2}{|c|}{ Symptom group } \\
\hline & Females & Males & Females & Males \\
\hline Number ${ }^{\top}$ & $1510(85.5)$ & $1281(83.7)$ & $4254(82.2)$ & $3896(79.4)$ \\
\hline Age yrs & $49.6 \pm 16.5$ & $50.1 \pm 16.1$ & $50.1 \pm 17.1$ & $51.5 \pm 17.0$ \\
\hline Weight $\mathrm{kg}$ & $70.8 \pm 12.5$ & $83.7 \pm 12.4$ & $72.7 \pm 14.2$ & $84.4 \pm 13.7$ \\
\hline Height $\mathrm{cm}$ & $163.9 \pm 6.4$ & $177.4 \pm 7.1$ & $163.7 \pm 6.4$ & $176.6 \pm 6.7$ \\
\hline Body mass index $\mathrm{kg} \cdot \mathrm{m}^{-2}$ & $26.3 \pm 4.4$ & $26.5 \pm 3.4$ & $27.2 \pm 5.2$ & $27.0 \pm 3.9$ \\
\hline \multicolumn{5}{|l|}{ Lung function } \\
\hline FEV1 L ${ }^{+}$ & $2.80(96.4)$ & $3.82(94.3)$ & $2.56(88.6)$ & $3.40(84.8)$ \\
\hline $\mathrm{FVC} \mathrm{L}^{+}$ & $3.44(97.5)$ & $4.85(97.3)$ & $3.25(92.6)$ & $4.52(92.2)$ \\
\hline \multicolumn{5}{|l|}{ Smoking habit } \\
\hline Never-smoker & 50.7 & $41.1^{* *}$ & 43.1 & $29.7 * *$ \\
\hline Exsmoker & 18.9 & $29.3^{* *}$ & 19.5 & $33.9^{* *}$ \\
\hline Current smoker & 30.0 & 29.6 & 37.3 & 36.2 \\
\hline Pack-yrs in ever smokers ${ }^{\S}$ & $11.5 \pm 8.8$ & $15.5 \pm 14.8^{* *}$ & $12.9 \pm 9.9$ & $17.9 \pm 15.6^{* *}$ \\
\hline \multicolumn{5}{|l|}{ Respiratory symptoms/diseases } \\
\hline $\begin{array}{l}\text { Attacks of wheezing or } \\
\text { breathlessness during } \\
\text { the last } 12 \text { months }\end{array}$ & 13.7 & 13.9 & 73.0 & 73.3 \\
\hline Ever having had asthma & 8.6 & 8.4 & 54.5 & 53.4 \\
\hline $\begin{array}{l}\text { Ever having used asthma } \\
\text { medication }\end{array}$ & 8.1 & 7.9 & 53.3 & $46.6^{* *}$ \\
\hline Current asthma & 5.6 & 4.6 & 33.8 & $30.9^{* *}$ \\
\hline Daily coughing in periods & 15.3 & $17.6^{* *}$ & 47.8 & $44.4 * *$ \\
\hline Cough with phlegm & 8.4 & 10.2 & 27.9 & 28.7 \\
\hline Chronic bronchitis & 3.2 & $5.1 *$ & 12.6 & $14.4^{*}$ \\
\hline \multicolumn{5}{|l|}{ Global SRH } \\
\hline Poor & 1.5 & 1.6 & 3.3 & $4.2 *$ \\
\hline Not so good & 27.4 & $23.1^{*}$ & 44.8 & $39.9 * *$ \\
\hline Good & 56.4 & 59.1 & 44.8 & $49.1^{* *}$ \\
\hline Very good & 14.7 & 16.1 & 7.1 & 6.8 \\
\hline
\end{tabular}

Data are presented as mean \pm SD or mean (\%) unless otherwise stated. ${ }^{\#}$ : excluded those who reported symptoms in the $5 \%$ random sample; ${ }^{\top}$ : (per cent of those invited to BONT phase I among participants at the main screening); ${ }^{+}: \%$ predicted; ${ }^{\S}$ : adjusted by age. In each sample the difference by sex was tested by the Chi-squared test for proportions and variance analyses for mean number of pack-yrs. FEV1: forced expiratory flow in one second; FVC: forced vital capacity; SRH: self related health. *: $\mathrm{p}<0.05 ; * *: \mathrm{p}<0.01$.

associated with $1.5 \%$ lower FEV1 \% in both sexes $(\mathrm{p}<0.05)$, compared with nonexposed. When the analyses were restricted to never-smokers, a minor and nonsignificant $(\mathrm{p}=0.07)$ lower FEV1 \% pred was found in females exposed to passive smoking compared with those without such exposure (fig. 2b).

Decreased FVC, FEV1, FEV1/FVC (fig. 3), and forced expiratory flow at $25-75 \%$ of forced vital capacity (FEF25-75) (data not shown) were associated with tobacco smoking in ever smokers according to both pack-yrs and current daily cigarette consumption ( $\mathrm{p}<0.01$ for trend). No sex difference in absolute values was found for any of the lung function parameters and this was independent of age. Age and height adjusted FEV1, FVC and FEF25-75 were associated with a reduction of 12,10 , and $27 \mathrm{~mL} \cdot \mathrm{s}^{-1}$ per pack-yr, respectively. However, this means that females have a larger reduction in these lung function parameters in \% pred terms than males. One pack-yr was associated with 0.52 and $0.32 \%$ lower FEV1 $\%$ pred in females and males $(\mathrm{p}<0.001)$, respectively, and the corresponding figures for $\mathrm{FVC} \%$ reduction were 0.28 and $0.16 \%(\mathrm{p}<0.001)$.

Respiratory symptoms, diagnosis, and self-rated health by lung function and sex

Females reported a higher prevalence of wheezing or breathlessness and coughing, independent of FEV1\% pred, compared with males for both the total BONT sample (fig. 4) and when the analyses were restricted to only the 5\% random sample. Further, females aged $>60$ yrs had significantly higher FEV1 \% pred compared with males, regardless of reporting respiratory symptoms or doctor-diagnosed respiratory disease $(\mathrm{p}<0.01)$ (fig. 5).

In the total BONT sample, SRH was reported to be "poor" in $2 \%$ and "very well" in $16 \%$ of cases, independent of sex. Independent of lung function, the category "well" was reported by fewer females than males (23.2 versus $27.8 \%$ ), with reciprocal results in the category "not very well" (both $\mathrm{p}<0.01)$. A similar pattern was found for $\mathrm{SRH}$, dichotomised in those reporting "positive" and "negative" score by FEV1\% pred adjusted for age and pack-yrs (fig. 6).

A decreased score in SRH was associated with specific respiratory symptoms, including attacks of wheezing, breathlessness, or cough, without any difference with sex. These results were not significantly influenced by pack-yrs, level of education and BMI as covariates in the model.

\section{Discussion}

A higher proportion of females reported respiratory symptoms compared with males, adjusted for smoking burden and lung function. Further, reporting of respiratory symptoms was associated with poorer $\mathrm{SRH}$ in both sexes, but females reported poorer SRH compared with males independent of 

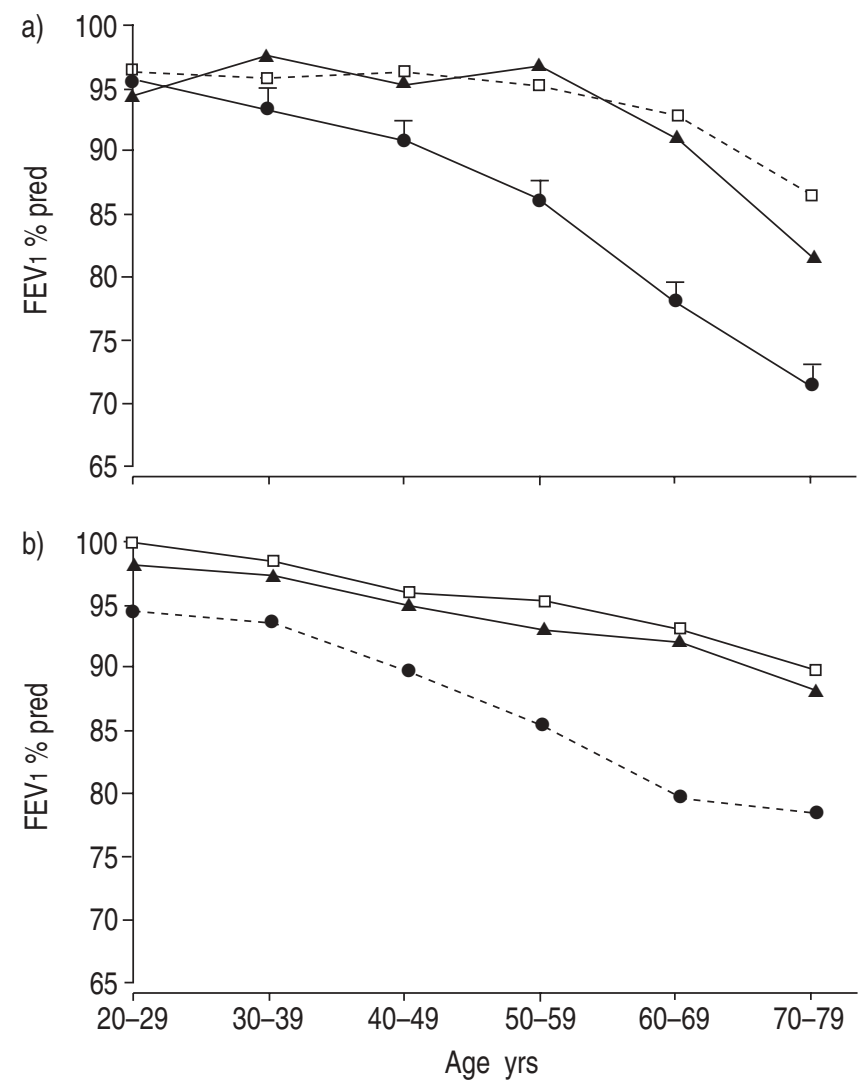

Fig. 2.-Forced expiratory volume in one second (FEV 1 ) in \% predicted by age, among never-smokers exposed ( $\boldsymbol{\Lambda})$ and not exposed ( $\square$ ) to passive smoke, and among ever-smokers $(\bullet)$ in a) males and b) females.

lung function. The results from this study confirm previous findings of a dose-dependent increase in prevalence of respiratory symptoms and a corresponding negative effect on lung function with tobacco smoking [12]. However, females had a larger reduction in lung function in terms of $\%$ pred than males.

BONT was part of a comprehensive cross-sectional study

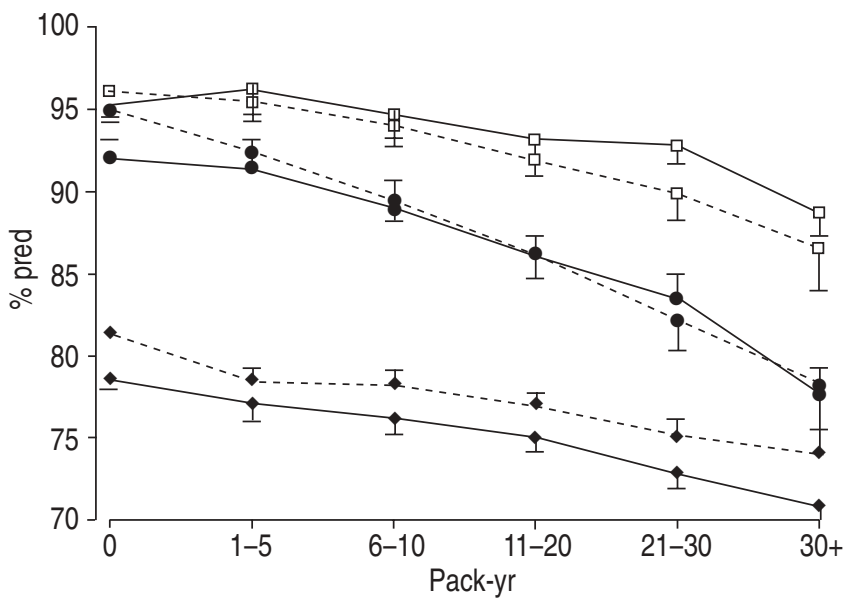

Fig. 3. - Age-adjusted forced expiratory volume in one second (FEV1) ( $\square$ ), forced vital capacity (FVC) $(\bullet)$ as \% predicted and FEV $1 / F V C$ $(\bullet)$ by pack-yrs in males $(-)$ and females (-----) in the total Bronchial Obstruction in the Nord Trøndelag study group (random sample 2,791 subjects and symptom group 8,150 subjects).

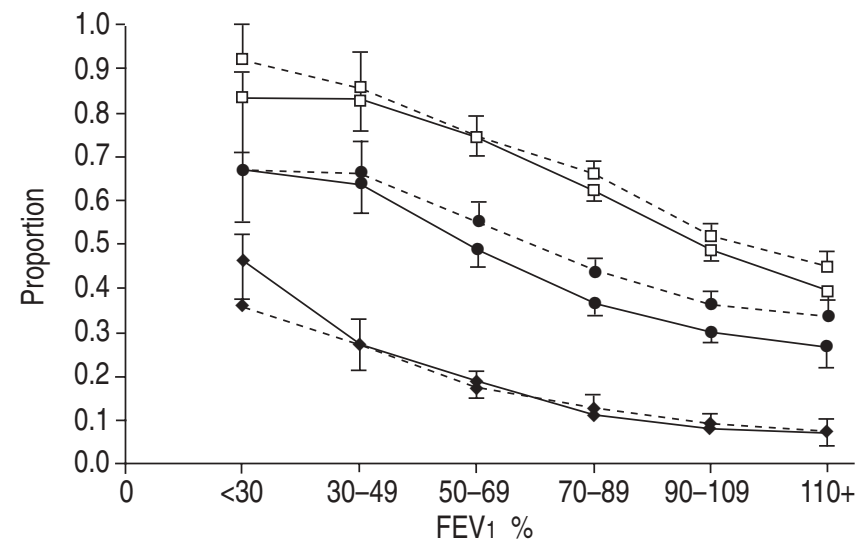

Fig. 4. - Proportion of subjects in the Bronchial Obstruction in the Nord Trøndelag study sample reporting respiratory symptoms by forced expiratory volume in one second $\left(\mathrm{FEV}_{1}\right) \%$ predicted in males (-) and females (-----), adjusted by age and pack-yrs. $\square$ : wheeze or breathlessness; $\bullet$ : daily cough in periods; $\diamond$ : chronic bronchitis.

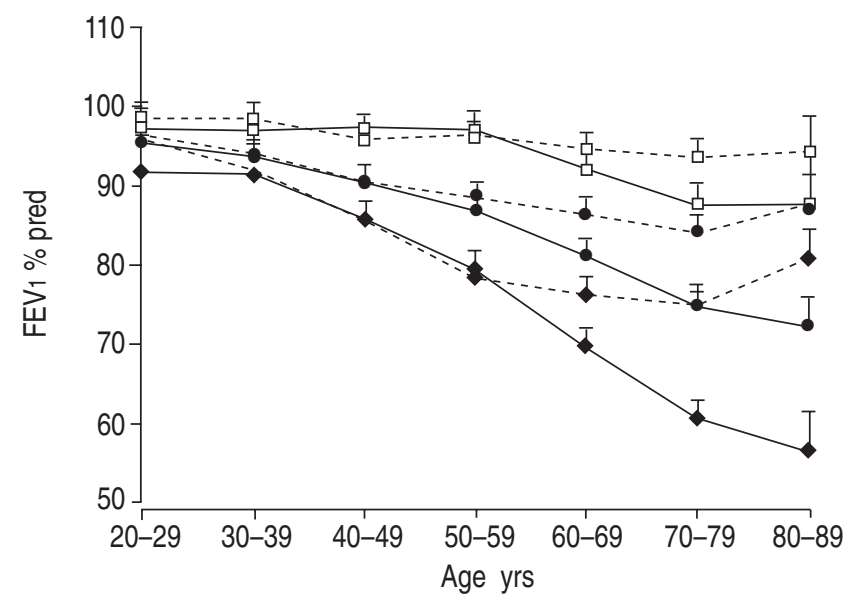

Fig. 5. - Forced expiratory volume in one second (FEV1) \% predicted in males (-) and females (------), reporting no respiratory symptoms and respiratory symptoms with and without diagnosis of respiratory disease, by age. $\square$ : no respiratory symptoms; $\bullet$ : respiratory symptoms; $\bullet$ : respiratory symptoms and doctor diagnosed asthma or chronic bronchitis/emphysema.

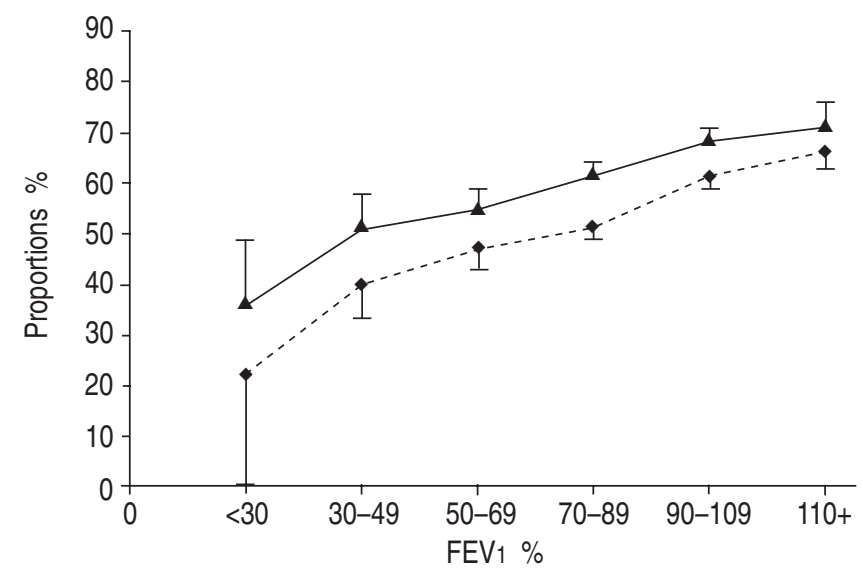

Fig. 6. - Age and pack-yrs adjusted proportions (\%) reporting "very well" or "well" to questioning on self-rated global health by forced expiratory volume in one second $\left(\mathrm{FEV}_{1}\right)$ and sex, with $95 \%$ confidence intervals in the total Bronchial Obstruction in the Nord Trøndelag study sample. $\boldsymbol{\Delta}$ : males; $\diamond$ : females. 
of a complete adult population, including a $5 \%$ representative random sample of the total population and a symptom group, both with high attendance rate [5]. A study of nonresponders at the main screening did not reveal any specific selection biases [5]. The level of industrial and traffic pollution is very low in Nord-Trøndelag County, Norway, the population is homogenous, and the combination of questionnaires and interviews secured high-quality data for the explored risk factors. Nevertheless, the authors fully realise the limitations of the cross-sectional design, and therefore report presence of associations and not causal relationships.

\section{Tobacco smoking and lung function}

Tobacco smoking has a noxious effect on the airways. In this study, a strong, dose-dependent association between tobacco smoking and reduced FEV1, FVC and FEV1/FVC was found in both sexes. This is in agreement with the results from a meta-analysis of eight large US populationbased studies [6] and a longitudinal study from Netherlands [13]. But, other cross-sectional studies, such as the Beijing respiratory health study [2], a Canadian study [14], the French Cooperative study [8], the Tucson Airways study [15] and both a cross-sectional and longitudinal study from Copenhagen $[4,16]$ have reported a greater decline in lung function among females than males, associated with tobacco smoking. On the other hand, opposite results have been found in both cross-sectional and longitudinal studies, such as the Six Cities study [17], the Tucson Airways Study [18], the cross-sectional part of the Netherlands study [13], the Copenhagen study (after redefining exclusion criteria, but not adjusting for quantity smoked) [19], an Italian study [20] and the UCLA study from Los Angeles [21]. Comparisons between crosssectional and longitudinal studies are distorted, as those with better lung function are more likely to continue in longitudinal studies [13].

The healthy-smoker effect (i.e. without respiratory symptoms) and different smoking prevalence could partly explain the divergent results found in previous studies, when neversmokers are used as reference groups. XU et al. [22] showed that in the studies reporting greater smoking effects on lung function in females than in males, there was a relatively low prevalence of male never-smokers (11-25\%), whilst the opposite results were found in studies with higher prevalence of male never-smokers $(27-43 \%)$. Given that "unhealthy" subjects (i.e. with respiratory symptoms) are a constant proportion of the population, and because such subjects with respiratory and cardiovascular diseases have a lower tendency to start or continue smoking compared with healthy subjects, the proportion of these in a never-smoking reference group would be higher in populations with a low prevalence of never-smokers. Any smoke-related difference between smokers and never-smokers would then be diluted. The present study, with a prevalence of never-smokers of $38.3 \%$ in males and $49.7 \%$ in females, is probably not prone to such prevalence effects.

Different sex effects of tobacco smoking could also be influenced by the fact that female never-smokers were older than female smokers, in contrast to that was found in males, but adjustments for age should take account of this.

\section{Tobacco smoking and respiratory symptoms}

The authors have previously reported that adjusted for age and smoking burden, more females than males reported respiratory symptoms, such as wheezing, breathlessness and cough without phlegm [5]. In the present study, similar sex associations independent of lung function were found, and significant higher FEV1 \% pred in females compared with males aged $>60$ yrs in asymptomatic and symptomatic subjects, independent of doctor-diagnosed lung disease or not. Even if tobacco smoking in females was associated with greater percentage reduction in FEV1, FVC, and FEF25-75 compared with males, this does not fully explain the discrepancy in symptom reporting related to smoking burden between sexes. There are many different contributory factors to this. First, females might be more aware of illness and diseases than males. Assuming that FEV1 and FVC reflected all deleterious effects of tobacco smoking in the airways, the present results of a higher prevalence of symptom reporting in females compared with males at similar levels of lung function, would have supported such an explanation. However, conflicting results on this issue have been reported. MACINTYRE et al. [23] did not find any sex differences in the reporting of conditions, including trivial and mental conditions. Further, GIJSBERs et al. [24] found that even if females, when compared with males, reported more physical symptoms, they reported similar illness behaviour. In addition, different work exposure rather than different vulnerability has been found to explain sex differences in health [25].

Secondly, there could be a selection bias among current smokers if symptomatic males succeeded in smoking cessation more often than symptomatic females. In the present population, males reported smoking cessation more frequently than females, regardless of reporting respiratory symptoms [5]. However, even if analyses revealed a lower OR for respiratory symptoms by number of pack-yrs when the analyses were restricted to never-smokers/exsmokers compared with neversmokers/current smokers, similar difference with sex in reporting symptom by pack-yr was found (data not shown).

Thirdly, respiratory symptoms might be more strongly associated with global health and less specific for lung diseases in females compared with males [8]. The authors' assessed global health by using a SRH measure with four steps, as this had been used previously in Norwegian population-based studies [9]. Generally, the differences between SRH measures are marginal, females' rate poorer or similar to males, and in both sexes SRH measurements are found to be powerful predictors of future morbidity and mortality [26]. In the present study, the association between respiratory symptoms and SRH was independent of sex, indicating a similar influence of respiratory symptoms on quality of life in males and females, independent of objective measurements, such as flow volume spirometry. Higher risk for reporting SRH "not very well" by pack-yr among females than among males is consistent with sex difference in association between pack-yrs and respiratory symptoms.

Fourthly, sex differences in symptoms could be due to differences in airway diameter. As the resistance to flow in a tube is inversely proportional to the fourth power of its radius, a similar reduction in radius in a small and large tube would influence the flow most in the former. In the present study, when including FEV1 \% pred and thus taking different airway calibre into account, the sex difference in respiratory symptoms was still present, as also found by LEYNAERT et al. [3].

Fifthly, symptoms could be a more sensitive parameter of vulnerability in the peripheral airways, compared with FEV1 and $\mathrm{FVC}$, reflecting changes mainly in the larger airways. There are differences in airway calibre and lung size between males and females of the same size, and this might influence the deposition of tobacco-smoke products [27]. Females with smaller airway diameter would thus theoretically be more vulnerable to noxious gases deposited in the peripheral airways. Experimental studies by WAGNER et al. [28] on 
patients with mild asthma, showed a considerable increase in peripheral resistance, despite having a normal lung function measured as FEV1 and FVC. WAGNER et al. [28] also showed a strong correlation between increase in peripheral resistance and degree of bronchial hyperresponsiveness to methacholine. Interestingly, studies have shown a higher smoke-related bronchial hyperresponsiveness in females compared with males [3] and lower cough threshold in females than males when they were exposed to cough stimuli (capsaicin) [29]. Further measurements of bronchial hyperresponsiveness in population-based studies might clarify this. So far, these have been mainly direct provocation tests (methacholine and histamine), but results regarding sensitivity and specificity of studies of simpler, indirect tests (mannitol) are promising for inclusion of such tests in large-scale studies [30].

Sixthly, there could be sex differences in validity of selfreported smoking behaviour and of inhalation pattern and exposure for passive smoking. Both estimation of pack-yrs and smoking behaviour have been reported to be fairly accurate in most studies [31, 32]. The authors do not have data on whether there are different inhalation patterns between sexes. Due to a higher prevalence of smokers and smoking burden in males compared with females, both smoking and nonsmoking females have probably been exposed to more passive smoking than males, and this would dilute any deleterious effect of tobacco smoking in females compared with males. However, including passive smoking in the analyses did not influence the results in the present study.

To conclude, smoking burden was associated with similar absolute reduction in expiratory lung function measures in males and females, meaning that females had larger relative reductions in lung function. However, adjusted for age and pack-yrs, more females than males reported respiratory symptoms and the category "not very well" on self-rated health, adjusted for lung function. The associations between respiratory symptoms and self-rated health were independent of sex. This might support the hypotheses that females have greater perceived vulnerability for the deleterious effect of tobacco smoking than males. Whether this increased perception of symptoms are reflecting unmeasured pathological changes in the peripheral airways in addition to changes reflected by lung function measurements such as forced expiratory volume in one second or forced vital capacity, cannot be answered in this study. Use of more sophisticated lung function measurements and/or prospective follow-up of those with and without reported symptoms are possible ways of establishing whether symptom perception is a more sensitive tool indicating early deteriorating changes in the lower airways.

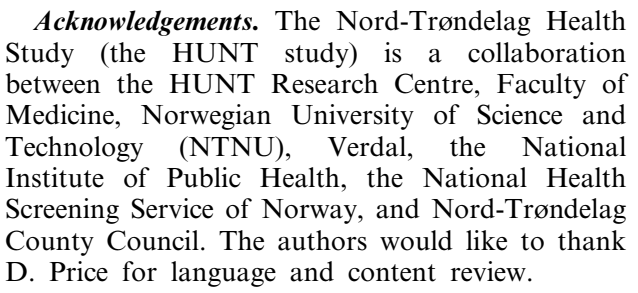
Study (the HUNT study) is a collaboration between the HUNT Research Centre, Faculty of Medicine, Norwegian University of Science and Technology (NTNU), Verdal, the National Institute of Public Health, the National Health County Council. The authors would like to thank D. Price for language and content review.

\section{References}

1. Gold DR, Wang X, Wypij D, Speizer FE, Ware JH, Dockery DW. Effects of cigarette smoking on lung function in adolescent boys and girls. N Engl J Med 1996; 335: 931937.
2. $\mathrm{Xu} \mathrm{X,} \mathrm{Li} \mathrm{B,} \mathrm{Wang} \mathrm{L.} \mathrm{Gender} \mathrm{difference} \mathrm{in} \mathrm{smoking} \mathrm{effects} \mathrm{on}$ adult pulmonary function. Eur Respir J 1994; 7: 477-483.

3. Leynaert B, Bousquet J, Henry C, Liard R, Neukirch F. Is bronchial hyperresponsiveness more frequent in women than in men? A population-based study. Am J Respir Crit Care Med 1997; 156: 1413-1420.

4. Prescott E, Bjerg AM, Andersen PK, Lange P, Vestbo J. Gender difference in smoking effects on lung function and risk of hospitalization for COPD: results from a Danish longitudinal population study. Eur Respir J 1997; 10: 822-827.

5. Langhammer A, Johnsen R, Holmen J, Gulsvik A, Bjermer L. Cigarette smoking gives more respiratory symptoms among women than among men. $J$ Epidemiol Community Health 2000; 54: 917-922.

6. Vollmer WM, Enright PL, Pedula KL, et al. Race and gender differences in the effects of smoking on lung function. Chest 2000; 117: 764-772.

7. Kauffmann F, Becklake MR. Sex and Gender. Eur Respir Mon 2000; 5: 288-304

8. Kauffmann F, Becklake MR. Maladies respiratoires obstructives. Un paradigme de la complexité des différences de santé entre femmes et hommes. In: Saurel-Cubizolles MJ, Blondel B, eds. La santé des femmes. Paris, Médecine-Sciences, 1996; pp. 209-233.

9. Wøien G, Øyen O, Graff-Iversen S. 22 years of cardiovascular surveys in Norwegian counties. Is the development in risk factors satisfactory? Nor J Epidemiol 1997; 7: 255-266.

10. American Thoracic Society. Standardization of Spirometry, 1994 Update. American Thoracic Society. Am J Respir Crit Care Med 1995; 152: 1107-1136.

11. Langhammer A, Johnsen R, Gulsvik A, Holmen TL, Bjermer L. Forced spirometry reference values for Norwegian adults: the bronchial obstruction in Nord-Trondelag Study. Eur Respir J 2001; 18: 770-779.

12. American Thoracic Society. Cigarette smoking and health. Am J Respir Crit Care Med 1996; 153: 861-865.

13. van Pelt W, Borsboom GJ, Rijcken B, Schouten JP, van Zomeren BC, Quanjer PH. Discrepancies between longitudinal and cross-sectional change in ventilatory function in 12 years of follow-up. Am J Respir Crit Care Med 1994; 149: 1218-1226.

14. Chen Y, Horne SL, Dosman JA. Increased susceptibility to lung dysfunction in female smokers. Am Rev Respir Dis 1991; 143: $1224-1230$.

15. Burrows B, Knudson RJ, Cline MG, Lebowitz MD. Quantitative relationships between cigarette smoking and ventilatory function. Am Rev Respir Dis 1977; 115: 195-205.

16. Lange P, Groth S, Nyboe GJ, et al. Effects of smoking and changes in smoking habits on the decline of FEV1. Eur Respir J 1989; 2: 811-816.

17. $\mathrm{Xu} \mathrm{X,} \mathrm{Dockery} \mathrm{DW,} \mathrm{Ware} \mathrm{JH,} \mathrm{Speizer} \mathrm{FE,} \mathrm{Ferris} \mathrm{BGJ}$ Effects of cigarette smoking on rate of loss of pulmonary function in adults: a longitudinal assessment. Am Rev Respir Dis 1992; 146: 1345-1348.

18. Camilli AE, Burrows B, Knudson RJ, Lyle SK, Lebowitz MD. Longitudinal changes in forced expiratory volume in one second in adults. Effects of smoking and smoking cessation. Am Rev Respir Dis 1987; 135: 794-799.

19. Lange $\mathrm{P}$, Groth $\mathrm{S}$, Nyboe J, et al. Decline of the lung function related to the type of tobacco smoked and inhalation. Thorax 1990; 45: 22-26.

20. Viegi G, Paoletti P, Prediletto R, et al. Prevalence of respiratory symptoms in an unpolluted area of northern Italy. Eur Respir J 1988; 1: 311-318.

21. Tashkin DP, Clark VA, Coulson AH, et al. The University College of Los Angeles (UCLA) population studies of chronic obstructive respiratory disease. VIII. Effects of smoking cessation on lung function: a prospective study of a freeliving population. Am Rev Respir Dis 1984; 130: 707-715.

22. Xu X, Weiss ST, Rijcken B, Schouten JP. Smoking, changes in smoking habits, and rate of decline in FEV1: new insight into gender differences. Eur Respir J 1994; 7: 1056-1061. 
23. Macintyre S, Ford G, Hunt K. Do women 'over-report' morbidity? Men's and women's responses to structured prompting on a standard question on long standing illness. Soc Sci Med 1999; 48: 89-98.

24. Gijsbers VWC, Huisman H, Kolk AM. Gender differences in physical symptoms and illness behavior. A health diary study. Soc Sci Med 1999; 49: 1061-1074.

25. Emslie C, Hunt K, Macintyre S. Gender differences in minor morbidity among full time employees of a British university. J Epidemiol Community Health 1999; 53: 465-475.

26. Eriksson I, Unden AL, Elofsson S. Self-rated health. Comparisons between three different measures. Results from a population study. Int J Epidemiol 2001; 30: 326333.

27. Mead J. Dysanapsis in normal lungs assessed by the relationship between maximal flow, static recoil, and vital capacity. Am Rev Respir Dis 1980; 121: 339-342.

28. Wagner EM, Liu MC, Weinmann GG, Permutt S, Bleecker ER.
Peripheral lung resistance in normal and asthmatic subjects. Am Rev Respir Dis 1990; 141: 584-588.

29. Fujimura M, Kasahara K, Kamio Y, Naruse M, Hashimoto T, Matsuda T. Female gender as a determinant of cough threshold to inhaled capsaicin. Eur Respir J 1996; 9: 1624-1626.

30. Leuppi JD, Brannan JD, Anderson SD. Bronchial provocation tests: The rationale for using inhaled mannitol as a test for airway hyperresponsiveness. Swiss Med Wkly 2002; 132: $151-158$

31. Patrick DL, Cheadle A, Thompson DC, Diehr P, Koepsell T, Kinne S. The validity of self-reported smoking: a review and meta-analysis. Am J Public Health 1994; 84: 1086-1093.

32. Bernaards CM, Twisk JW, Snel J, Van Mechelen W, Kemper HC. Is calculating pack-years retrospectively a valid method to estimate life-time tobacco smoking? A comparison between prospectively calculated pack-years and retrospectively calculated pack-years. Addiction 2001; 96: $1653-1661$. 